\title{
A SUPERVISED E-SMART BASED LEARNING \& POPULATION STUDY IN EASTERN TRAI REGION OF UTTAR PRADESH INDIA - A FEASIBLE STUDY
}

\author{
Vinay Shukla ${ }^{1}$, A.K.Pandey ${ }^{2}$, Rahul Singh ${ }^{3}$, Shrawan Kumar ${ }^{4}$ \\ ${ }^{I}$ Department Of Computer Science \& Engineering, Institute Of Technology \& Management, Chehari, Maharajganj UP \\ India- 273303 \\ ${ }^{2}$ Department Of Applied Sciences, Institute Of Technology \& Management, Chehari, Maharajganj UP India- 273303 \\ ${ }^{3}$ Department Of Mechanical Engineering, Institute Of Technology \& Management, Chehari, Maharajganj UP India- \\ 273303 \\ ${ }^{4}$ Department Of Computer Science \& Engineering, Institute Of Technology \& Management, Chehari, Maharajganj UP \\ India- 273303
}

\begin{abstract}
Due to rapid advancement in information technology, digital revolution creates a new era \& scope in technology based learning system (TBLS). Considering the scenario a place which is extremely poor in every aspect of human development index (HDI) so called TRAI region of eastern Uttar Pradesh. New portable and electronic devices take place of old text books in this region. In this study we introduced some key questions with novel emerging e-Smart based learning environment. Smart based learning simply means that learning and teaching by electronic devices. Our study also established some key findings especially in human quality based development $(H Q B D)$ in this region such as thinking ability, living standered, human value, future based life planning etc. We also observe during our study, living standered are significantly improve and also this things create a new space to eradicate the poverty allevation in trai region. For our study we take data of 800 hundred students from different colleges of this region as well as concerned demographic data of rural areas. During study we also focus \& delineate to ask people about what are the changes they observe or found when they adopt new way of learning.
\end{abstract}

Keywords: TBLS, HDI, HQBD, Trai Region, Smart Learning etc.

\section{INTRODUCTION}

Wisdom and education are key factor in human development and these are backbone of any developing society or emerging empowerment in any populaton which deserve to survive with human values. But considering the fact that, the region which poorely established in all aspect of human development can not get small things easily. This region only based on analog type of development where one can buy books and read and unable to buy laptop to get better education. Students have to buy bulk book and read but it is not possible to carry whole book while travelling one place to other or moving one to other place. In such cases technology based learning or device induced learning (DIL) or digital based learning (DBL) will help to improve learning ability in any situation. Off course advancement in modern digital cutting technologies specially in information communication technology (ICT) set a new parameter for smart based learning environment to get better learning and thinking ability (TA)[1]. Rapid development of communication technologies around the whole world creates a massive opportunity in education and its dependent services. Smart based learning still in nascent stage or in early stages of evolution. But around the world especially in USA faculty and students are realizing the potential of smart based learning[2]. Smart based learning driven by students and faculty which has high impact to develop new skills to tackle upcoming challnages in $21^{\text {st }}$ century[4].
In 2000 few projects based on smart based learning in whole world mostly focused on computer based test or learning. Undoubtedly still smart based learning phenomenon are relatively new[3]. But while evolution of new smart phone devices and its opearting devices create a new span for smart based learning.

\section{WHY EASTERN TRAI REGION?}

Eastern trai region (ETR) of Uttar Pradesh as we know poorly established by nature or man made, such as human development are low in all aspect establishing such technologies in this region are challange in every aspect. Here one can face poor electricity which is very key factor to boost basic infrastucture development in this region. We took one part of eastern trai region of Uttar Pradesh so called MAHARAJGANJ. According to census of 2011 total popluation of district is $\mathbf{2 6 , 6 5 , 2 9 2}$.[11] This district is very close to our neighbouring country Nepal, and this region share one of longest international boundary with Nepal.

People's of this region are very low in human development index as compare to other districts of Uttar Pradesh. One can also found very small number of indistries . Beacuse of this reason migration rate are very high people's fall menatlly and get involve in bad things. But once we set up a small 
both of smart based learning for local people we observe and found rapid growth in human value index(HVI) such as education, living stander, thinking and other aspect of human development. In our study we establish knowledge based Smart plaza (KBSP) and also smart phone based environment to educate the people of this region. We call this a new paradigm shift in Supervised based learning environment[5]. It is well said that knowledge leads to new scope of thinking \& availbility of new space to obtain the necessary things for staying healthy.

\section{CONNECTED WORK}

Shiva Kanaujia et al. [6], discussed about smart based learning and concept in Indian aspect. New challenges of smart based Learning for the students and instructors are described by authors in [5]. Paper summarised that in online or distance Learning course, smart based Learning presents a host of new support requirements, and institutions must provide the appropriate resources to address them. Alyne Rothberg et. al. [6] has suggested organizational strategies for accessing Learning opportunities with having the availability of the broadband connection. Nilay M.Yajnik [7] had discussed about the Next Generation Internet. T. Rama Devi et al.[8] presented initiation of National Institute of Rural Development (NIRD) using ICT tools for the training of persons involved in rural development programs of central and state governments. Deepshikha Aggarwal et.al.[9], suggested that use of smart based Learning in vocational and informal training is very effective in a developing country like India where majority of population is illiterate and residing in rural areas. If we look trai region we found that lack of university infrastructure is not availbale by this people of this region can only access information only from smart based devices. Cyberspace which is a very cheap solution and moreover will raise the level of education, literacy and economic development.

\section{DATA COLLECTION \& FIELD SURVEY}

For our study purpose we choose eastern trai region of Uttar Pradesh and its one of remotely district Maharajganj. We choose around 800 students from different institutions based in this regions and also population data and demographic data around 400 hundred with rural data of different tehsils and we took data from our students from Institute (Institute Of Technology \& Management), they came from different regions of this place. Data are sampled from different towns of this district like Maharajganj urban/rural, Nautanwa,Nichlaul, Siswa, Ghugali \& Pharenda.

\section{RESULT AND DISCUSSIONS}

Smart based learning are basic entities for participants to get part in the study. The learners are divided into groups to provide information on their socio-economic characteristics which made it possible to compare them as well as portray the structure of each sample. The results obtained from groups are compared in terms of gender, age and education. The result is analysed in terms of satisfaction from smart based learning, current use of material and expectation from the digital based learning.

\section{CONCLUSION}

Smart devices based learning is highly emerging knowledge tool now a days. It has wide scope in developed as well as in developing countries. The areas which are undeveloped and not so educated get attraction of digital based Learning. Smart-Learning provides a method of delivering knowledgable contents through different electronic secondary media storage tools. The main constraint identified in this process is availability of proper bandwidth, willingness of smart based learners and some learning habit to deliver the material to learners. Overall, $70 \%$ participants found smart based learning is beneficial to rural areas for knowledge, better job opportunities, and promotions and to learn new developing technologies in the market. Especially focusing towards rural areas it helps in developing people's social and mental ability.

\section{REFERENCES}

[1]. Rimmi Anand et al 2012 "E-Learning and Its Impact on Rural Areas". I.J.Modern Education and Computer Sceinec 46-52

[2]. Policy Brief 2010 “ Mobile learning for quality education and social inclusion"

[3]. H.Uzunboylu et al 2009 " Using mobile learning to increase environment awarness" Computers \& Education 52 381-389.

[4]. Kumar Anuj et al 2010 “ An Exploratory study of Unsupervised Mobile learning in Rural India” ACM .

[5]. Kaur Amritpal et al 2013. "A new method of learning: M-learning " WCECS USA.

[6]. Shiva Kanaujia et al. "E-Education in India: Pace of Learning on a Hi-Tech Path", 2nd International CALIBER, New Delhi, 11-13 February, 2004.

[7]. EDUCASE Chapter 6, "Impact and Challenges of ELearning", Supporting E-Learning in Higher Education, Center for Applied Research, vol.3, 2003.

[8] Alyne Rothberg, Janet Bailey, Karen Ballard, "ELEARNING IN RURAL ENVIRONMENTS", http://www.swdsi.org/swdsi2012/proceedings_2012/papers/. ../PA150.pdf

[9]. Nilay M.Yajnik, "E-Learning Technologies for Rural India", http://www. cdac.ernet.in/html/pdf/ Session2.3.pdf [10]. Dr. T. Rama Devi, “E-Learning Tools and Technologies for Rural Development Community with special reference to training: Experiences of National Institute of Rural Development", DRTC - ICT Conference on Digital Learning Environment, 11th -13th January, DRTC, Bangalore, 2006.

[11]. Deepshikha Aggarwal, "Role of E-Learning in A Developing Country Like India", 3rd National Conference; Computing For Nation Development, February 26 - 27, 2009 Bharati Vidyapeeth's Institute of Computer Applications and Management, New Delhi, INDIACom2009.

[12]. Survey report based on Popluation register census 2011, Govt. Of INDIA. 